Asst. Prof. Dr. Meltem Yurtçu

Inonu University Department of Educational Science

Assoc. Prof. Dr. Serpil Pekdogan ${ }^{1}$

Inonu University at Department of Preschool Education

Malatya, Turkey
Original scientific paper

UDC: 37.032

DOI: $10.5937 /$ IstrPed2002248Y

\title{
KNOWLEDGE MAPPING ON TEMPERAMENT IN EARLY CHILDHOOD: A VISUALIZED ANALYSIS USING CITE SPACE
}

\begin{abstract}
In this study, the social network structure of the studies conducted in the early childhood towards the concept of temperament was examined. The research was considered as a descriptive study since it examined the relation between the existing studies according to the citations. The concept of temperament in early childhood has taken its place in the literature as a concept that began to be studied in 1955. 1025 studies on this subject in the Web of Science database were examined. Studies conducted between 1975-2020 were analyzed. In this study, Cite Space program, one of the social network analysis programs, was used. Documents were examined in relation to co-citations by authors, journals, countries and sources. As a result of the examinations, it was concluded that the most cited country was the United States, the most cited author Mary K. Rothbart, and the most cited journal Child Development. As a result of examining the co-references in the documents, 18 clusters named using the LLR (log-likelihood) algorithm were obtained. The names of the clusters and the most cited articles were determined in accordance with the network structure. At the same time, it is possible to see which clusters are more active in which periods and when the co-citations are analyzed according to the references and which articles are referred to more frequently. The current studies on this subject have been included in child obesity risk, postnatal plasticity revisited and extended and dispositional negativity clusters. With the results of this research, a map of information is presented to the researchers who want to study on the subject of temperament in early childhood. It can direct the researchers according to their sub-fields. It gives information about important sources, authors, and journals about the subject of interest, according to the tendency of the researcher. In addition, the researcher could see current issues or what topics the literature lacks. Therefore, as with this topic, authors can obtain detailed information about the subject area with such bibliometric studies while choosing the field of study.
\end{abstract}

Keywords: Temperament, early childhood, social network analysis, co-citation.

\footnotetext{
'serpilpekdogan.sp@gmail.com
} 


\section{Introduction}

The whole of the innate characteristics that determine the child's unique behavior style is defined as temperament. Temperament includes individual differences and provides information about the child's characteristics (Kristal, 2005; Goldsmith et al., 1987).

Different definitions of temperament have been made by many researchers. While Carey (2017) has expressed temperament as a characteristic pattern of the individual's behavioral style, reactions to his/her inner and outer world and his experiences, Thomas and Chess (1977) have revealed that there are nine types of temperament and have stated that temperament has characteristics that are the activity level, rhythmicity, approach, adaptability, intensity, sensory threshold, mood, distractability and persistence (Carey, 2017). In line with these characteristics, they determined three temperament classifications as an easy, difficult, and slow response. While children with easy temperaments can easily adapt to their diet, sleep routines, and environment, children with difficult temperaments are those who cannot easily adapt to the environment and whose nutrition and sleep routines are irregular. Slow-response children, on the other hand, are difficult to adapt to the environment and exhibit timid behaviors (Kristal, 2005; Keogh, 2003)

Buss and Plomin (1984) have taken the approach of Thomas and Chess (1977) further, and have stated that temperament was the pioneer of personality development in later developmental periods, it was brought along with innate genetic features and that it was unchangeable. They have discussed temperament in emotionality, activity, and sociability categories. Emotionality refers to sensory and behavioral arousal, activity refers to mobility, socialization refers to preferring to be with others over being alone (Buss \& Plomin, 1984). Rothbart defines temperament as individual differences between self-regulation and reactivity. According to Rothbart, temperament is genetically based and influenced by the environment. He has stated that temperament does not change completely, some of its dimensions change (Kristal, 2005). Besides, Cloninger has defined harm avoidance, novelty seeking, reward addiction, and persistence as dimensions of temperament. Cloninger has suggested that these four temperaments can be found in a person in various combinations genetically independent of each other (Cloninger \& Svrakic, 2000).

The vital importance and developmental process of temperament have attracted the attention of researchers since the past years. Many studies have been conducted on temperament and problem behaviors, peer relationships, relationships with the social environment, temperament characteristics at different ages. There are meta-analysis studies encountered on the concept of temperament in the literature. Zaninotto et al. (2016) have examined 57 studies on four types of temperament characteristics of Cloninger indexed in PubMed, SCOPUS, PsychINFO, and EM-BASE databases. In their studies, they have discussed the distribution, sampling methods, sample sizes, and working models of four types of temperament. As a result of the study, they have found that different study groups were formed on different temperament characteristics and different measurement tools were used. Else-Quest et al. (2006) have examined the gender variable by meta-analysis in temperament studies in which children between the ages of 3 and 13 were selected as a sample. In their studies, they have examined 1641 articles published between 1960 and 2002 in the PsycINFO database on temperament in the fields of psychology, psychiatry, and educational sciences. As a result of the study, it has been stated that girls have easier and 
adaptable temperaments, boys have more difficult temperaments and their activity levels are higher.

Since temperament contains characteristics, it is seen that the studies in the literature are associated with many variables. Kampman and Poutanen (2011) have discussed the studies addressing the relationship between temperament and depression, with the meta-analysis method. In the study, 4022 studies indexed in Web of Science (ISI), PsycINFO, and PsycArticles databases between 1991 and 2010 have been examined. The findings of the study have shown that depression is related to the temperament characteristics of the person. Similarly, metaanalysis studies that have discussed the relationship of temperament with psychiatric disorders (Miettunen \& Raeuvori, 2012), meta-analysis studies that have discussed the relationship between temperament dimensions defined by Cloninger and different variables (Miettunen et al., 2007; Miettunen et al., 2008) were included in the literature.

The importance of temperament in the life of the individual since early childhood and many factors associated with it illustrates that the subject is interesting and important. However, when meta-analysis studies are examined, it is seen that temperament is generally addressed in adulthood and is associated with psychiatric disorders. However, it is seen that studies, in which articles on temperament in early childhood are visualized descriptively, are not included in the literature. This study will greatly contribute to the field in terms of including 1025 studies on early childhood temperament between 1975-2020 and different social network analysis. In this context, answers were sought for the following questions regarding the articles reviewed:

1. How are citation networks structured by countries?

2. How are citation networks structured by authors?

3. How are citation networks structured by journals?

4. How are citation networks structured by sources?

\section{Method}

This study was based on examining articles on temperament in early childhood and visualizing these articles descriptively. There is bibliometric software such as "Bibexcel", "Science of sciencetool", "VOS Viewer" and "VantagePoint" that visualize statistical information descriptively (Seyedghorban, et al., 2015). In addition to this software, the "CiteSpace" Program was used. Citespace program was used in line with the purpose of the research. Citespace is a java application that analyzes and visualizes the wide network structure obtained from bibliometric data (Zhao \& Wang, 2011). Citespace is a program developed to map information fields, explain the relationship between different disciplines, evaluate the state of research, to reveal the latest studies, and be used in the prediction of trending issues that arise according to the analysis of the bibliographic records of related publications (Chen, 2014; Liu, Yin, Liu \& Dunford, 2015). The program propounds many network structures to identify leading research fields, to find the most producing countries and institutes, to define the distribution of main journals, to identify main authors and authors citing each other (Zhao \& Wang, 2011). While providing visualization, these programs use databases based on different approaches. These databases are WoS, Scopus, and Google Scholar. WoS and Scopus are commercial databases, evaluating citations and studies, and are seen as a contemporary database and pioneer with continuous and up-to-date data (Seyedghorban, Jekanyika-Matanda, \& LaPlaca, 2015; Jasco, 2005; Feng, Zhang, Du \& Wang, 2015). 
In this study, citation indexes according to the data set updated on 15.01.2020 in the Web of Science database ("Science Citation Index Expanded (SCI-EXPANDED)" and "SocialSciencesCitation Index (SSCI)" continue from 1980 to the present; "Arts \& Humanities Citation Index" (A \& $\mathrm{HCl}$ )" continues from 1975 to the present; "Conference ProceedingsCitation Index- Science (CPCI-S) "and" Conference ProceedingsCitation IndexSocialScience \& Humanities (CPCI-SSH)" continue from 1990 to the present; "BookCitation Index- Science (BKCl-S)" and "BookCitation Index - SocialSciences \& Humanities (BKCl-SSH)" included in 2005; and "EmergingSourcesCitation Index (ESCI)" included in 2015) were used.

\section{Data required for research}

The concepts of "child temperament", "children temperament", "childhood temperament", "early child temperament", "early children temperament" and "early childhood temperament" from the Web of ScienceTMcore collection database were linked with the conjunction "OR" and the search was made in abstract, author, keywords and Keywords Plus. In total, 1025 studies conducted between 1975 and 2022 on this subject have been reached. These studies are in 69 different categories, particularly in fields such as Psychology developmental, psychiatry, psychology clinical. When studies were examined by document types, $912(84.67 \%)$ of these studies were articles, 52 (4.82\%) were papers, 44 (4.08\%) were reviews, $35(3.249 \%)$ were papers, $14(1.29 \%)$ were chapters, and the other parts were constituted by early appearance, letter, editorial materials.

The studies included in the study were mostly published in English (1001 English, 11 German, 5 Spanish, 2 Turkish, 1 each in Japanese, Korean, Russian, French, Dutch, Czech).

In this research, attention has been paid not to use studies with the same content in more than one field. Only two studies were published as papers and articles, and no-repeat or duplication was encountered in other studies. Therefore, research was carried out with 1025 studies without removing data from the data set. A total of 32,108 citations were found in the study. The $\mathrm{H}$ index was 85 . Information on the frequencies of published studies and citations by years was given in Figure 1 . 

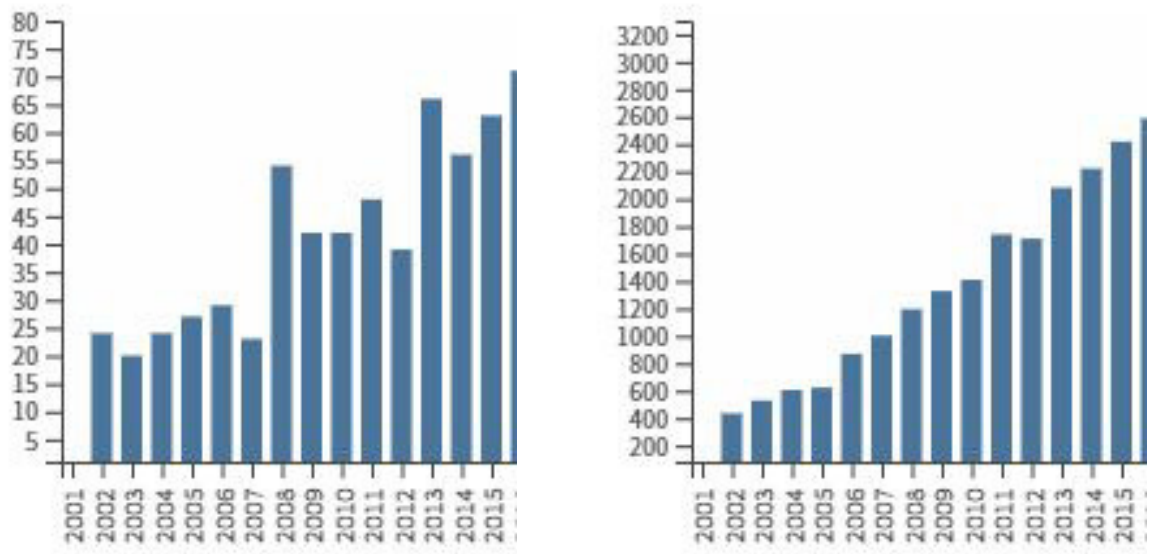

Figure 1. Total publications by years

Figure 2.Number of citations by years

When looking at studies in general, it is seen that these studies and citations have increased in recent years.

\section{Findings}

Analysis results were obtained according to 1025 studies conducted over a period of 43 years. For these analyzes, the network structure of common citations by countries, authors, journals and sources was examined. Besides, the period of the citations by sources was included, and the relationship of the studies with each other by year was discussed.

\section{The network structure of the citations by countries}

In the network structure, 62 nodes and 123 network connections were formed. The density value of this network structure was found to be 0.065 . This value can be expressed as the density is not excessive. Two important metrics provide information about the structural properties of the network. These are the mean Silhouette and Modularity $\mathrm{Q}$ values (Chen, 2014). It is acceptable when the Modleritiy $Q$ value is between 0.4 and 0.8 and shows the connection and relationship between the clusters (Liang, Luo, \& Zhong, 2018). Being high of this value indicates that the clusters are separated logically (Chen, 2014). The high mean Silhouette value indicates that the contents of the clusters are similar, in other words homogeneous (Chen, 2014; Liang et al., 2018). The mean Silhouette value and Modularity Q value obtained from citations by countries are 0.2464 and 0.3617 , respectively, and it can be said that this network structure is not homogeneous. When a cluster is created with citations by countries, the fact that the articles are conducted in different branches or subjects may explain the low value of Modularity Q. 


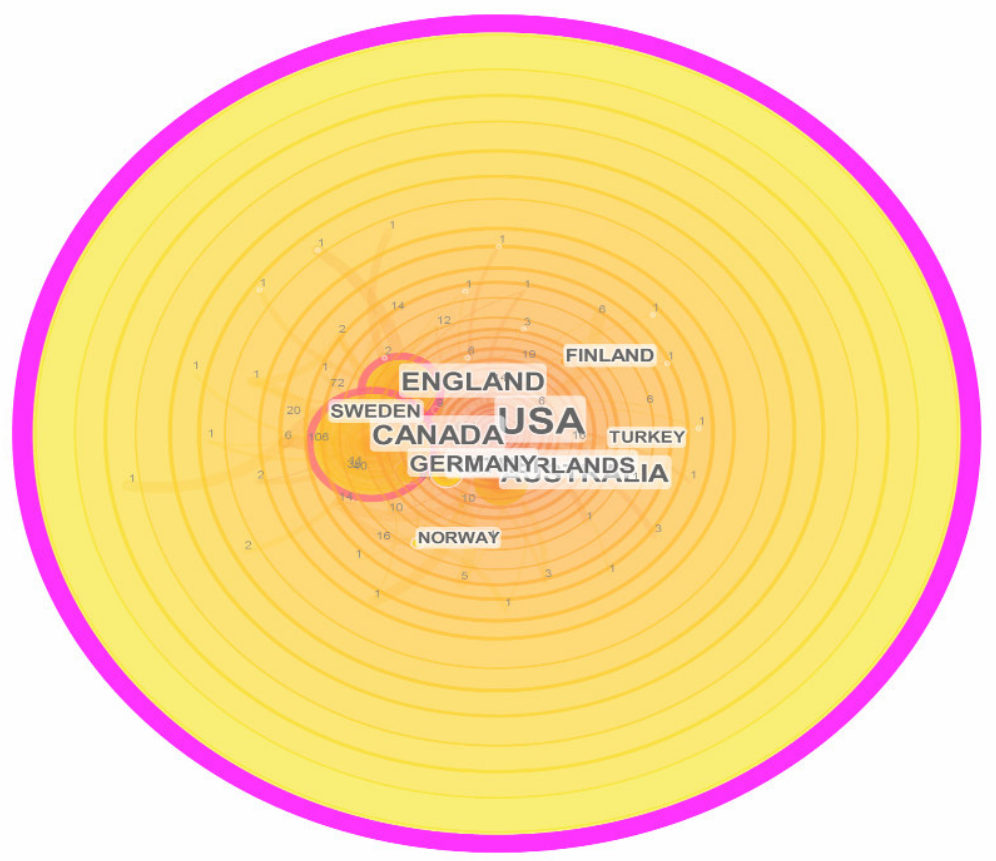

Figure 3. The Network Structure of the Citations by Countries

The size of the nodes varies by the number of citations (Dongxiao, Bo, Isabelle \& Changyong, 2004; Qi, Chen, Hu, Song \& Cui, 2019). As seen in Figure 3, it is seen that the country with the highest number of citations is the United States of America. The countries shown with the purple ring have a significant effect on this network map (Qin \& Hou, 2009) and represent centricity (Liang et al., 2018; Qi, Chen, Hu, Song \& Cui, 2019).The USA has the largest purple ring and is the most-cited (634) country. In the other purple rings, Canada is represented with 106 citations, England with 76 citations and Australia with 67 citations, respectively. When the countries ranked by the citation number examined, the Netherlands (40 citations), Germany (35 citations), Switzerland (20), Finland (19), Turkey (16), and Norway (16) are included in this ranking.

Therefore, it can be said that the countries that contribute to this field and where studies are carried out in this field are the United States of America, Canada, and England. It can be stated that the studies of our country in this field are also attracting attention.

\section{The network structure of citations by authors}

In the network structure obtained by authors, 988 nodes and 7603 network connections were found, the density was obtained as 0.0156 , and it can be stated that the network density is low because the citations are low. The mean Silhouette value and Modularity $\mathrm{Q}$ value indicating the importance of the network were obtained as 0.2703 and 0.4397 , respectively. In this case, it can be said that the clusters formed by the citations of the networks by authors 
are acceptable. It was observed that the homogeneity of the citations by authors of the networks was weak. The reason for this can be interpreted as the authors benefited from various sources in their studies on temperament in early childhood and conducted studies in various sub-fields.

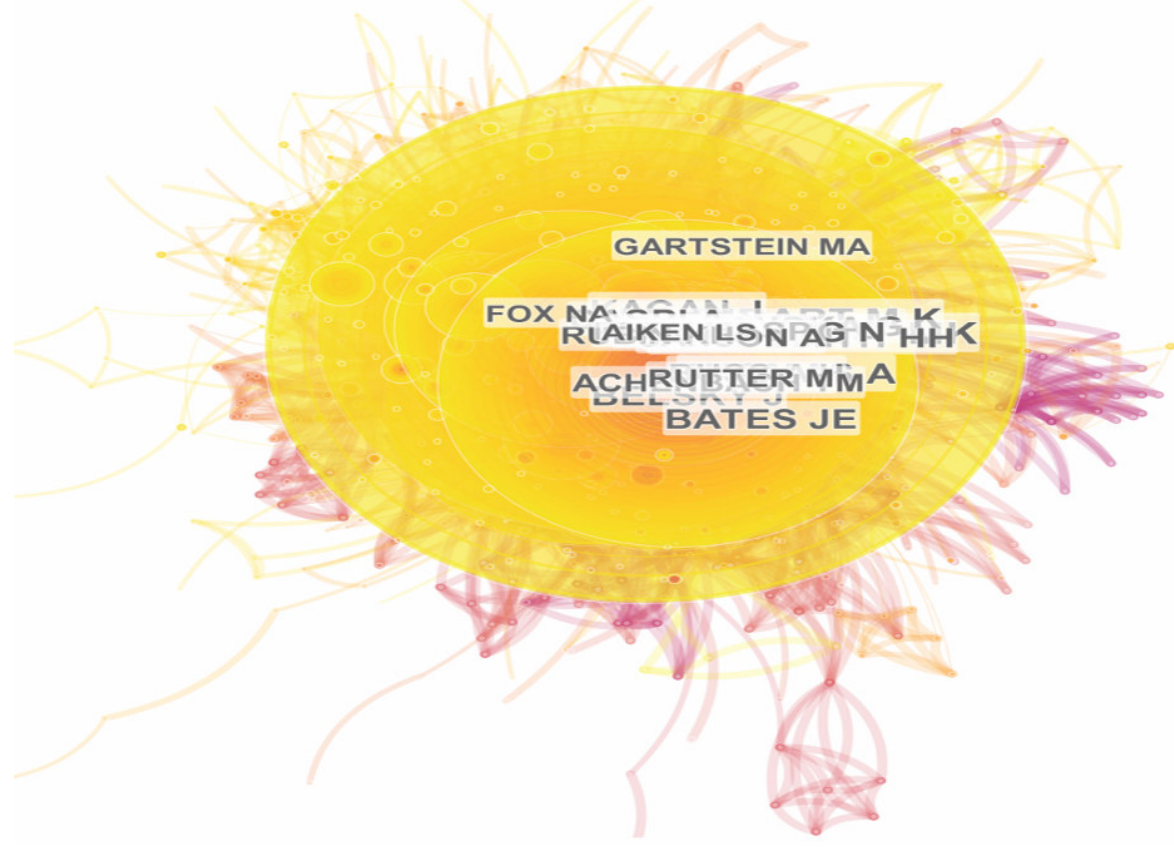

Figure 4. The Network Structure of Citations by Authors

Among the most cited (406-199) authors in the network structure, authors such as Mary K. Rothbart (she received 406 when she was named Rothbart MK; 323 citations when she was named Rothbart M K), Alexander Thomas (275), Jerome Kagan (235), Jay Belsky (231), Grazyna Kochanska (228), H. Hill Goldsmith (225), John E. Bates (206), Nancy Eisanberg (199) and Avshalom Caspi (199) are included. The fact that the networks are in different colors indicates that they are in different periods (Chen and Chen, 2005; Dongxiao, Bo, Isabelle \& Changyong, 2004; Qi, Chen, Hu, Song \& Cui, 2019; Liang et al., 2018). The dark colors of the networks can be expressed as that these studies have been conducted in previous years and that they are current studies as they approach the lighter color.

\section{The network structure of the citations by journals}

The density value obtained regarding the network structure was obtained as 0.022 . This value shows that the density is low. Regarding this network structure, it has been observed that there are 851 nodes and 7973 network connections. The mean Silhouette value and Modularity $Q$ value, which will show the formation of the network in a logical framework, were obtained as 0.2294 and 0.4162 , respectively. Similar to the network structure of the citations obtained by authors, it was found that the clusters formed by the citations in the journals were at acceptable levels and the homogeneity of the citations in the journals was weak. In this case, it can be stated that the subfields of the studies on this subject in journals differ. 
Figure 5. The Network Structure of Citations by Journals

When the studies of "temperament in early childhood" between 1975-2020 were examined, it was observed that the most cited journal was "Child Development". The most cited journals and their number of citations were given in Table 1.

Table 1. Most cited journals and citation numbers

\begin{tabular}{ll}
\hline \hline Citation Numbers & Journals \\
\hline 799 & Child Development \\
669 & Developmental Psychology \\
577 & Journal Of Child Psychology And Psychiatry And Allıed Disciplınes \\
509 & Development And Psychopathology \\
480 & Psychological Bulletın \\
440 & Journal Of The American Academy Of Child and Adolescent \\
415 & Psychiatry \\
404 & Journal Of Abnormal Child Psychology \\
353 & Journal Of Personality and Social Psychology \\
\hline
\end{tabular}


Therefore, it can be stated that the contribution of the "Child Development" journal is great regarding this subject field. The coefficient that determines the importance of journals and shows their attracting more attention besides the number of citations is centricity. Centricity shows the role of nodes in information networks, and other nodes show the importance of another node (Qin \& Hou, 2009). Each journal has a centricity coefficient. Information on the centricity coefficients of the journals was given in Table 2;

Table 2. Journals and centricity coefficients

\begin{tabular}{ll}
\hline \hline Coefficients & Centricity \\
\hline 125 & American Journal Of Orthopsychıatry \\
80 & American Psychologist \\
73 & British Journal Of Psychıatry \\
71 & Advances in Developmental Psychology \\
68 & Archıves Of General Psychıatry \\
66 & Temperament development \\
63 & Annual Review of Psychology \\
62 & Braın Behaviorand Immunity \\
61 & Chıld Psychiatry\& Human Development \\
58 & Journal Of Abnormal Chıld Psychology \\
\hline
\end{tabular}

As seen in Table 2, it is seen that the journal contributing the most to the field is the American Journal Of Orthopsychiatry with 125 centricities. Therefore, it can be stated that this journal is more connected with other journals. When the scope of the top 10 journals with high centricity is examined, it is seen that temperament in the early childhood period is mostly discussed in psychology and pediatricsjournals.

\section{The network structure of citations by sources}

The density value obtained regarding the network structure was obtained as 0.0062 . This value shows that the density is low. Regarding this network structure, it has been observed that there are 1298 nodes and 5192 network connections. The mean Silhouette value and Modularity $Q$ value, which will show the formation of the network in a logical framework, were obtained as 0.3588 and 0.8562 , respectively. According to these values, it can be stated that the citation network structure of the journals is not homogeneous, however, they are clustered within a logical structure, and therefore citation networks are reliable. 


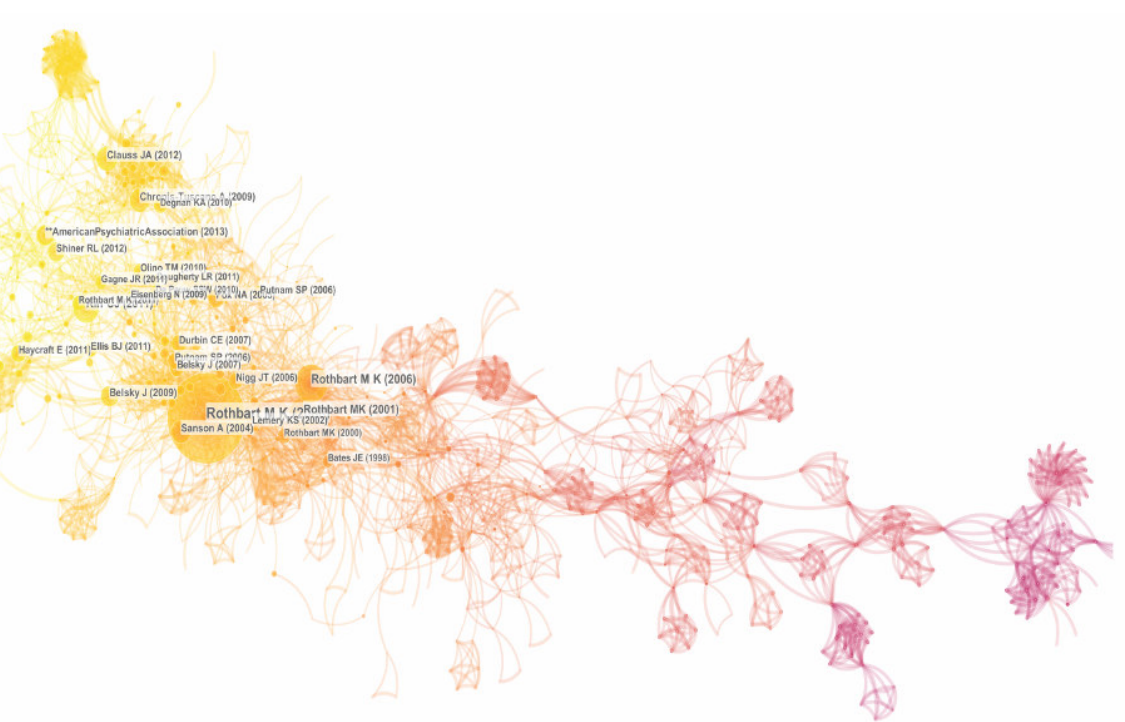

Figure 6. The Network Structure of Citations by Sources

As can be seen from the Network structure, which shows the relationship of each study with other studies, it is observed that the studies of Rotbart, M.K. play an important role. Although different colored networks show different periods, the fact that most attention-drawing studies are given in orange is an indication that these studies have been carried out in the recent past. In the clusters obtained, the colors represent the same periods as the colors in the same networks.

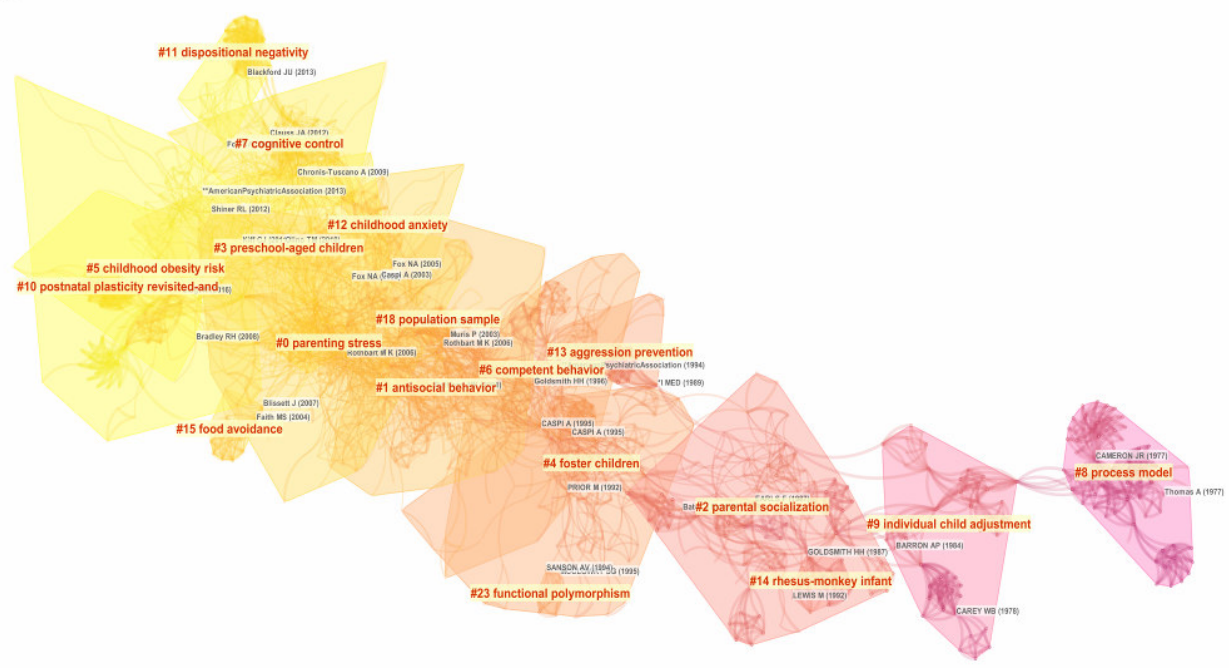

Figure 7. The Cluster Structure of Citations by Sources 
Studies were clustered by the citations of similar studies. A total of 18 clusters were formed. Clusters are named according to three algorithms. These algorithms are TF*IDF, LLR, and MI algorithms. Algorithms serve to characterize the nature of the cluster to be defined (Chen, 2014). In this study, the names of the clusters are named with the LLR algorithm based on the log-likelihood ratio.

Table 3. Information on clusters obtained by sources

\begin{tabular}{|c|c|c|c|c|}
\hline \multicolumn{3}{|c|}{ IDNumberSilhouetteLabel (LLR) } & \multicolumn{2}{|c|}{$\begin{array}{l}\text { Citations Name of the clusters } \\
\text { Year }\end{array}$} \\
\hline 0157 & 0.751 & Parenting stress & 2005 & $\begin{array}{l}\text { Kiff, Cara J.; Lengua, Liliana J.; Zalewski, } \\
\text { Maureen (2011) Nature and nurturing: } \\
\text { parenting in the context of child } \\
\text { temperament. Clinıcal Chıld and Family } \\
\text { Psychology Review, V14, P51 DOI } \\
\text { 10.1007/s10567-011-0093-4. }\end{array}$ \\
\hline
\end{tabular}

$\begin{array}{lll}132 & 0.805 & \text { Antisocial behavior } 2000\end{array}$

Shiner, R \& Caspi, A. (2003) Personality differences in childhood and adolescence: measurement development, and consequences. Journal Of Child Psychology and Psychıatry and Allıed Disciplınes, 44(1): 232. Doi 10.1111/1469-7610.00101

Dadds, M.R. \& Salmon, K. (2003) Punishment insensitivity and parenting: temperament and learning as interacting risks for antisocial behavior. Clinical Child and Family PsychologyReview. 6(2). 69-86. DOI 10.1023/A:1023762009877.

$21060.852 \quad$ Parental 1987 PRIOR, M (1992) Childhood temperament. socialization Journal Of Child Psychology and Psychiatry, 33(1).doi. 10.1111/j.1469-7610.1992.tboo863.x.

$398 \quad 0.705 \quad$ preschool-aged 2008 Marakovitz, S. E., Wagmiller, R. L.,Mian, N. children D., Briggs-Gowan, M. J \&Carter, A.S. (2011).Lost toy? Monsters undert hebed? contributions of temperament and family factors to early internalizing problems in boys and girls. Journal Of Clinıcal Chıld and Adolescent Psychology, 40, doi 10.1080/15374416.2011.546036.

$487 \quad 0.879 \quad$ Foster children $1993 \quad$ Orme, J.G. \& Buehler, C. (2001) Foster family characteristics and behavioral and emotional problems of foster children: a narrative review. Famıly Relatıons, 50, P13 dio 10.1111/j.1741-3729.2001.00003.x.

\begin{tabular}{|c|c|c|c|}
\hline 584 & 0.888 & $\begin{array}{l}\text { Childhood obesity2012 } \\
\text { risk }\end{array}$ & $\begin{array}{l}\text { Bergmeier H., Paxton S.J., Milgrom, } \\
\text { J., Anderson, S.E., Baur, L., Hill, B., Lim, } \\
\text { S., Green, R.\& Skouteris, H. (2020). Early } \\
\text { mother-child dyadic pathways to childhood } \\
\text { obesity risk: a conceptual }\end{array}$ \\
\hline
\end{tabular}




\begin{tabular}{ccl} 
& & model.Appetite,doi \\
& \multirow{3}{*}{$0.843 \quad$ competentbehavior1995 } & 10.1016/j.appet.2019.104459. \\
& Rimm-Kaufman, S. E.,Early, D. M., Cox, M. J., \\
& Saluja, G., Pianta, R. C., Bradley, R. H., \\
& \&Payne, C. (2002). Early behavioral \\
& attributes and teachers' sensitivity as \\
& predictors of competent behavior in the \\
& kindergarten classroom. Journal of Applied \\
& Developmental Psychology, 23(4), 451-470. \\
& doi 10.1016/S0193-3973(02)00128-4. \\
\hline
\end{tabular}

The largest cluster in the formed clusters is the one shown with \#0 and named "parentingstress" according to the LLR algorithm. This cluster contains 157 articles in total. The Silhouette value, which shows the significance of the network structure formed with each other by the elements of this cluster, is 0.751 , and this value indicates that the network structure of the cluster is significant. The average publication years of the studies in this cluster are 2005. The study cited the most on this cluster is the study "Nature and nurturing: parenting in the context of child temperament" by Kiff, C. J.,Lengua, L. J. and Zalewski, M. (2011).

The second-largest cluster is the cluster shown with \#1 and named as "anti-social behavior" according to the LLR algorithm. This set contains 132 articles in total. The most cited studies in this cluster are two, and these studies belong to Shiner and Caspi (2003) which is "Personality differences in childhood and adolescence: measurement development, and consequences"; and to Dadds and Salmon (2003) which is "Punishment insensitivity and parenting: temperament and learning as interacting risks for anti social behavior".

According to the number of elements in other clusters, their sizes are as follows; cluster \#2 with the name of parental socialization consists of 106 studies, cluster \#3 with the name of preschool -aged children consists of 98 studies, cluster \#4 with the name of foster children consists of 87 studies, cluster \#5 with the name childhood obesity consists of 84 studies, cluster \#6 with the name competent behavior consists of 77 studies. It is possible to see the articles that most actively refer to these clusters in Table 3.

Silhouette values, which show the homogeneity levels of the clusters, vary between 0.705 and 0.888 , and according to these values, it can be stated that the clusters consistently combine within themselves.

The timeline shows in which time frames the studies in the clusters are more effective (Kim \& Chen, 2015; Santos, 2015 ). The locations of the clusters in the time tunnel were examined to see the relationship between the studies in the clusters by years. 


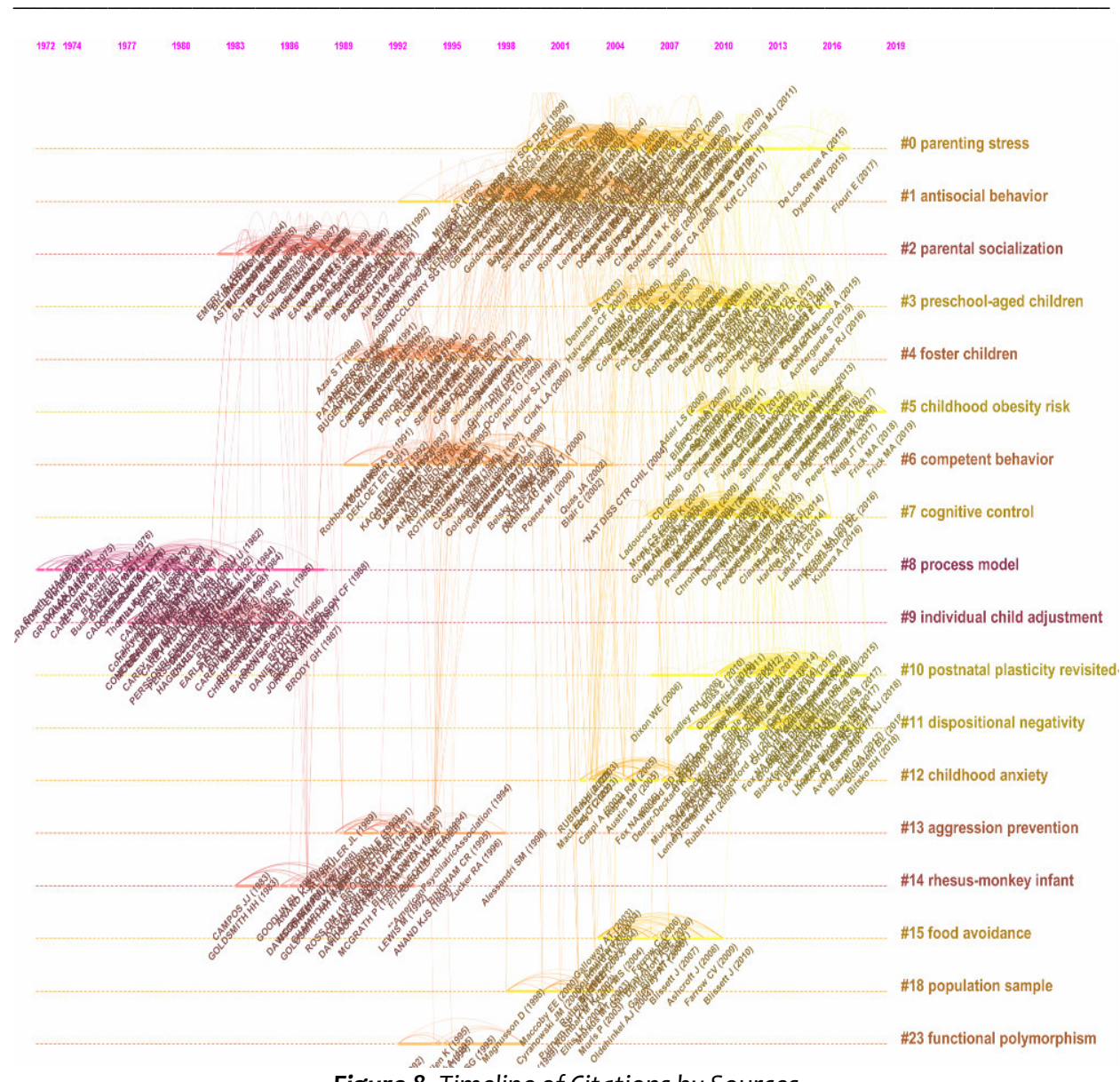

Figure 8. Timeline of Citations by Sources

In total, 18 clusters that could be significant were obtained. Since some of the clusters obtained were not found to be significant, they were not included in the figures as clusters. As it is possible to see the names of the clusters in Figure 7 and Table 3, the information about these significant 18 clusters can be seen in Figure 8 . As can be seen in the timeline, in the earliest studies on temperament in early childhood periodare concentrated in the process model and individual child adjustment clusters in the 1970s. As seen in the time tunnel, the studies carried out in the past years are given in red, and the more recent studies in yellow. Besides, it is seen that the orange-colored studies were carried out between 1980-2000, so the structure of the networks was lightened towards current studies. Current studies, on the other hand, on this subject are included in child obesity risk, postnatal plasticity revisited and extendedand dispositional negativityclusters. According to the networks showing the relationship of the articles in the clusters with each other, cluster \# 1 named antisocial behavior showed a relationship the most with other clusters. 


\section{Conclusion, Discussion, and Recommendations}

Bibliometric research can be expressed as a type of research that can provide more active use of descriptive research and guide many studies. While these researches can be carried out with many software, this study was conducted using the CiteSpace program. Although the concept of temperament in early childhood very popular, this study has been carried out to examine in which fields this concept is studied mostly in the literature. The data used in the study were obtained from the website of the Web of Science. In total, the research was conducted on 1025 studies.

The network structure of common citations for countries, authors, journals, and sources was examined with the analysis. When common citations were examined by country, it was observed that the most cited country was the United States of America, followed by Canada and England.

When the network structure of common citations was examined by authors, it was concluded that the most cited author was Mary K. Rothbart. When the network structure of citations by journals was examined, it was found that the journal that made the most contribution regarding the subject, that is, the most cited, was the "Child Development" journal. Besides, the journal that has the most interaction with other journals and therefore has the highest centricity coefficient was found as the American Journal of Orthopsychiatry. In the examination of the common citation network structure by countries, authors, journals, and sources, it was observed that the structures were not homogeneous. This indicates that there is a variety in the citations and sub-study fields for the subject field studied. It was observed that the clustering processes of the network structure by authors and journals were acceptable, and the suitability of this differentiation was high by sources. Therefore, it can be accepted that the citations that are related to each other fall into the same cluster. This situation will be important for researchers who want to study on temperament in early childhood on the examination of authors, journals, and sources in sub-subject fields, not to leave any deficiencies in their studies. Significantly 18 clusters were obtained as a result of clustering by sources. With the study that made the most citations to clusters, the most cited articles in these clusters were reached. At the same time, when common citations are examined by sources, it is possible to see which clusters are more active in which periods and which clusters' articles are cited more.

This research will provide map information to researchers who want to study in this subject field and will guide them. Determining the most important sources, authors, journals, etc. according to the tendency of the subject of interest will be more reliable in terms of conducting studies based on these documents. Besides, the researcher can see current issues or in which subjects the literature is deficient. Therefore, authors can obtain detailed information about the subject field with such bibliometric studies while choosing their field of study. 


\section{NOTES:}

\section{Ethical Approval}

All procedures performed in studies involving human participants were in accordance with the ethical standards by the 1964 Helsinki declaration and its later amendments or comparable ethical standards.

\section{Informed Consent}

Informed consent was obtained from all individual participants included in the study.

\section{Conflict of Interest}

On behalf of all authors, the corresponding author states that there is no conflict of interest.

\section{References}

Buss, A. H., \& Plomin, R. (1984). Theory and measurement of EAS, temperament: early developing personality traits. New Jersey: Hillsdale.

Carey, W. B. (2017). Editorial Perspective: Whatever happened to temperament?. Journal of Child Psychology and Psychiatry, 58(12), 1381-1382.

Chen, C. \& Chen, Y. (2005). Searching for Clinical Evidence in Cite Space. AMIA 2005 Symposium Proceedings, 121.

Chen, C. (2014). The Cite Spacemanual. Retrieved from: http://cluster.ischool.drexel.edu/ rchen/citespace.

Cloninger C. R. \& Svrakic D. M. (2000). Personality disorders. Comprehensive Textbook of Psychiatry. USA: Lippincott Williams \& Wilkins.

Dongxiao, G. B. L., Isabelle, B., \& Changyong, L. (2004). Temporal Evolution, Research Themes, and Emerging Trends in Case-Based Reasoning Literature. Retrived from: http://ceur-ws.org/Vol-2004/paper1.pdf.

Else-Quest, N. M., Hyde, J. S., Goldsmith, H. H., \& Van Hulle, C. A. (2006). Gender differences in temperament: a meta-analysis. Psychological bulletin, 132(1), 33.

Feng, F., Zhang, L., Du,Y. \& Wang, W. (2015). Visualization and quantitative study in bibliographic databases: A case in thefield of university-industry cooperation. Journal of Informetrics 9, 118-134.

Goldsmith, H. H., Buss, A. H., Plomin, R., Rothbart, M. K., Thomas, A., Chess, S., ... \& McCall, R. B. (1987). Roundtable: What is temperament? Four approaches. Child development, 505-529.

Jacso, P. (2005). As wemaysearch - Comparison of majorfeatures of the Web of Science, Scopus, and Google Scholar citation-based and citation-enhanced databases. Current Science, 89, 9.

Kampman, O., \& Poutanen, O. (2011). Can onset and recovery in depression be predicted by temperament? A systematic review and meta-analysis. Journal of Affective Disorders, 135(1-3), 20-27.

Keogh, B. K. (2003). Temperament in the classroom: Understanding individual differences. Paul H Brookes Publishing. 
Kim, M. C \& Chen, C. (2015). A scientometric review of emerging trends and new developments in recommendation systems. Scientometrics, 104, 239-263.

Kristal J. (2005). The temperament perspective: Working with children's behavioral styles. Michigan (USA): Paul H Brooks Publishing.

Liang C., Luo, A. \& Zhong, Z. (2018). Knowledge mapping of medication literacy study: A visualized analysis using CiteSpace. SAGE Open Medicine, 6(1-10). DOI: 10.1177/2050312118800199.

Liu, Z., Yin, Y., Liu, W. \& Dunford, M. (2015). Visualizing the intellectual structure and evolution of innovation systems research: a bibliometric analysis. Scientometrics, 103:135-158.

Miettunen, J., \& Raevuori, A. (2012). A meta-analysis of temperament in axis I psychiatric disorders. Comprehensive Psychiatry, 53(2), 152-166.

Miettunen, J., Lauronen, E., Kantojarvi, L., Veijola, J., \& Joukamaa, M. (2008). Intercorrelations between Cloninger's temperament dimensions-A metaanalysis. Psychiatry research, $160(1), 106-114$.

Miettunen, J., Veijola, J., Lauronen, E., Kantojarvi, L., \& Joukamaa, M. (2007). Sex differences in Cloninger's temperament dimensions-a meta-analysis. Comprehensive psychiatry, 48(2), 161-169.

Qi, Y., Chen, X., Hu, Z., Song, C. \& Cui, Y. (2019). Bibliometric Analysis of Algal-Bacterial Symbiosis in Waste water Treatment. International Journal of Environmental Researchand Public Health, 16, 1077. doi:10.3390/ijerph16061077.

Qin C. J. \&Hou H. Q. (2009). Knowledge map: a new areas of information management and knowledge management. Chin J Acad Lib; 27, 30-37.

Santos, A. B. (2015). Open Innovation research: trends and influences- a bibliometric analysis. Journal of Innovation Management, 3, 2, 131-165.

Seyedghorban, Z., Jekanyika_Matanda, M. \& La Placa, P. (2015). Advancing theory and knowledge in the business-to-business branding literature. Journal of Business Research. doi: 10.1016/j.jbusres.2015.11.002.

Thomas, A. \& Chess, S. (1977). Temperament and Development. New York: Brunner/Mazel.

Van Raan, A. F. J. (2005). For your citations only? Hot topics in bibliometric analysis. Measurement: Interdisciplinary Researchand Perspectives 3 (1), 50-62.

Zaninotto, L., Solmi, M., Toffanin, T., Veronese, N., Cloninger, C. R., \& Correll, C. U. (2016). A meta-analysis of temperament and character dimensions in patients with mood disorders: Comparison to healthy controls and unaffected siblings. Journal of affective disorders, 194, 84-97.

Zhao, R. \& Wang, J. (2011). Visualizing the research on pervasive and ubiquitous computing. Scientometrics $86,593-612$.

\section{Biographical notes:}

Asst. Prof. Dr. Meltem YURTÇU: Dr. Yurtcu graduated from Atatürk University Division of Mathematical Education in 2010. In 2013, she completed her master's degree in same university. She completed her doctorate in Hacettepe University Division of Educational Measurement and Evaluation in 2018. She has been at Virginia Commonwealth University as visiting scholar in 2017. Her research focused on test equating, DIF, Bayesian Approach.

Assoc. Prof. Dr. Serpil PEKDOGAN: Dr. Pekdogan graduated from Inonu University Faculty of Education, Department of Preschool Education in 2009. In 2011, she completed graduate 
education at the Inonu University Institute of Educational Sciences Department of Preschool Education, and in 2015, she received Ph.D. at Gazi University Department Institute of Educational Sciences, Department of Preschool Education. She is working Inonu University at Department of Preschool Education She has studies in children decision making skills, children socail skills, child abuse and neglect, preschool education and teacher training 